\title{
Perception of word-final inserted vowels and syllabicity in Italian
}

\author{
Veronica Miatto \\ Department of Linguistics, Stony Brook University, US \\ https://doi.org/10.36505/ExLing-2020/11/0034/000449
}

\begin{abstract}
Perceptual evidence is provided in favour of the non-syllabicity of word-final vocalic elements in consonant-final nonce words in Italian. These are optionally present after words ending in consonants, and their syllabicity status is debatable. In the experiment, speakers listened to stimuli of nonce words presenting variable duration of word-final schwas and judged whether the stimuli were monosyllabic or disyllabic. The results strongly suggest that speakers of Veneto Italian do not phonologically distinguish between nonce words that present a word-final schwa and those that do not. In fact, stimuli were generally judged as monosyllabic. The results of the study support previous research stating that word-final schwas in Italian are non-syllabic, phonetic vowels.
\end{abstract}

Keywords: epenthetic vowels, intrusive vowels, perception, Veneto Italian

\section{Introduction}

The present study addresses the ability of epenthetic vowels to be syllable nuclei. Specifically, perceptual-based evidence is used to determine whether Italian native speakers will perceive word-final inserted vowels as syllabic. Consonant-final words in Italian might be adapted with a word-final vocalic element, so that a word like 'jet' can be adapted as [dzet] or as [dzet:ə], with the word-final inserted vowel preceded by lengthening of the consonant, but much variation is reported.

The phonological status of this inserted vowel is unclear. Some authors consider it a syllabic (canonically epenthetic) vowel that constitutes the nucleus of a new syllable and it is inserted to repair a violated structure (Bafile 2002 and later work, Passino 2008, Broniś 2016). On the other hand, other authors consider it a non-syllabic (intrusive) vowel, which does not form a new syllable and appears under prosodic and metrical pressures (Grice et al. 2015, Grice et al. 2018) or a vocalic element that is part of the release of the consonant (Repetti 2012, Miatto et al. 2019).

In particular, Miatto (2020) provides evidence from a production study that word-final inserted vowels in Italian are non-syllabic. While the duration measurements are somewhat ambiguous in their phonological underlying structure, repetition and place of articulation effects imply that the inserted

ExLing 2020: Proceedings of 11 th International Conference of Experimental Linguistics, 12-14 October 2020, Athens, Greece 
schwas are non-syllabic, and their presence is due to a need to aid the perceptibility of word-final consonants.

These results, compounded with the characteristics of the vocalic element itself, which satisfy Hall's (2006, 2011) diagnostics of intrusive vowels (vs. epenthetic vowels) in optionality, quality, and variability, strongly suggest that word-final schwas are non-syllabic. The present study provides additional, perceptual-based evidence that strengthens Miatto's (2020) conclusions.

\section{Methodology}

The study featured 13 native Italian speakers from Veneto (North-Eastern Italy), aged 19 to 36 years old.

In the experiment, they listened to 6 nonce words that followed the template $\mathrm{C}_{1} \mathrm{C}_{2}$, such as /vik/. $\mathrm{C}_{2}$ was a lengthened voiceless stop, followed by a wordfinal inserted schwa that would range from 0 to $100 \mathrm{~ms}$, in incremental steps of $25 \mathrm{~ms}$. No spelling or visual transcription was provided for the speakers, and the stimuli were produced by a native speaker of that variety of Italian. The stimuli were repeated in two blocks, in which the speakers had to judge whether the stimulus was constituted by one or two syllables.

Additionally, in the first block speakers were also asked to repeat aloud the stimuli they were hearing, to assess whether a stimulus presenting a word-final vocalic element would encourage the speakers to produce one too. The presence of a word-final schwa in the speakers' production was determined through spectrogram analyses.

\section{Results}

Results of 13 participants show that speakers overwhelmingly perceive words like [vik:] or [vik:ə] as one syllable. In fact, out of 773 tokens, 718 (93\%) were perceived as one syllable, while $55(7 \%)$ were perceived as two syllables.

Statistical analysis performed with a generalized linear mixed-effects model found that speakers are 3.15 times more likely to identify as disyllabic stimuli that end in coronals or labials than velars $(95 \%$ confidence interval (CI) 1.04..9.53 times, $p=0.0377$ ). In Miatto's study (2020), coronals and labials pattern together too, contrasting with velars. However, in that study, velars were less likely to be followed by a word-final schwa than labials or coronals, which would predict the opposite perceptual result to the one found in this study. While these opposing effects will have to be explained in future studies, I will note that both in the stimuli and in speakers' production, velars had abnormally long VOTs for Italian, reaching $70 \mathrm{~ms}$, which might have influenced the perception of word-final schwas.

The duration of the word-final schwa has an almost significant effect. Speakers tend to be more likely to identify a stimulus as disyllabic as the duration of the schwa increases, especially between 50 and $100 \mathrm{~ms}$ (CI 0.92..5.89 times, $p=0.069$ ). 
When asked to repeat the stimuli, speakers would sometimes insert wordfinal vocalic elements, even if the stimulus did not contain one itself and vice versa. They displayed much variation in their production of inserted schwas, presenting one between $0 \%$ and $97 \%$ of the tokens. Crucially, the correlation coefficient between their rates of vowel insertion and whether they were perceiving one or two syllables was very low, and non-significant (cor $=0.098$, $p=0.06$ ). This is depicted in Figure 1, with the blue line indicating percentages of disyllables identified (regardless of the presence or duration of the final schwa), and the green line indicating the percentages of vowel insertion produced.

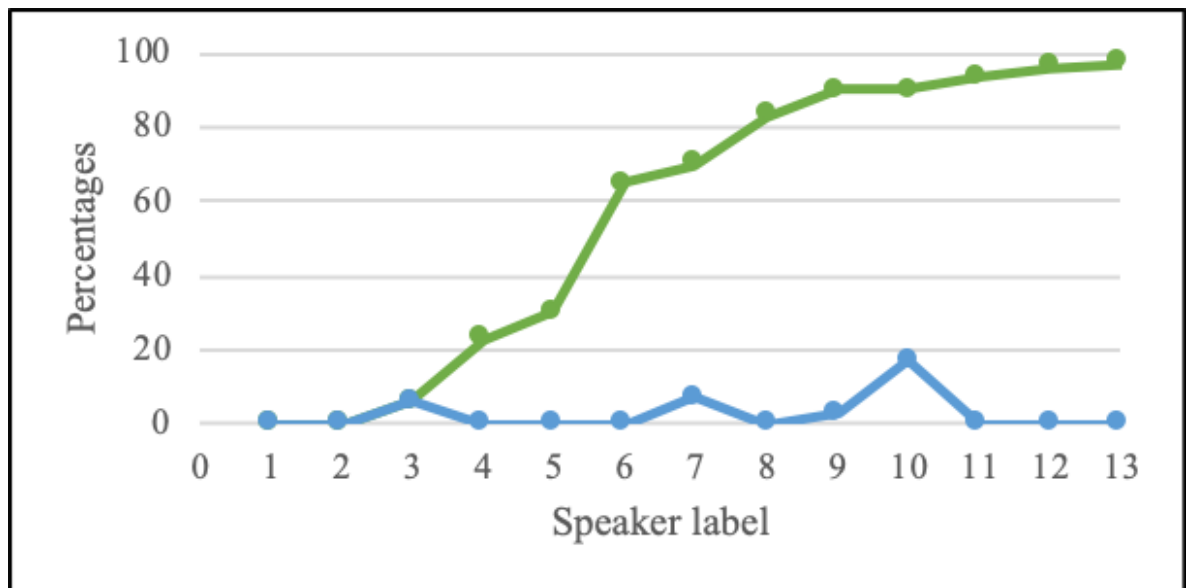

Figure 3. Correlation between percentages of disyllables perceived (blu) and word-final vocalic elements inserted (green) for each speaker

Some speakers would select some nonce words as disyllabic consistently, e.g. speaker S7 pressed the key for two syllables only for the nonce word [pit] (5/10 tokens), while speaker S3 perceived as disyllabic only the word [dit] and [kip] in some instances (3/10 and 2/10 respectively). This suggests that some speakers may have perceived some tokens as disyllabic because they had categorized that one particular lexeme as disyllabic, and not due to the presence of a word-final vocalic element.

\section{Conclusions}

The speakers' clear judgement of the stimuli as monosyllabic indicates that speakers cannot perceive the potentially syllabic difference between nonce words with an inserted vowel and nonce words that lack one. This conclusion is strengthened by the fact that the increasing duration of the word-final schwa was not a significant factor in the speakers' decisions, and the non-correlation 
between the presence of the word-final vocalic element in the stimuli and whether the speakers would insert it in production.

In summary, the results of this study show that speakers are not able to discriminate between stimuli with a word-final schwa and stimuli that lack one. Both cases were mainly perceived as monosyllabic words, suggesting that the inserted vowel, when present, is a phonetic vowel and does not participate in syllabification processes, contrary to what was suggested in previous literature.

\section{References}

Bafile, L. 2002. Il trattamento delle consonanti finali nel Fiorentino: Aspetti fonetici. Atti delle XXIII Giornate G.F.S., Pisa, Italy.

Broniś, O. 2016. Italian vowel paragoge in loanword adaptation. Italian Journal of Linguistics 28, 25-68.

Grice, M., Savino, M., Caffò, A., Roettger, Tb. 2015. The tune drives the text - Schwa in consonant-final loan words in Italian. Proc. 18th International Congress of Phonetic Sciences (ICPhS 2015). Glasgow, UK.

Grice, M., Savino, M., Roettger, Tb. 2018. Word final schwa is driven by intonationThe case of Bari Italian. Journal of the Acoustics Society of America 143, 2474.

Hall, N. 2006. Cross-linguistic patterns of vowel intrusion. Phonology 23, 387-429.

Hall, N. 2011. Vowel epenthesis. In van Oostendorp, M., Ewen, Cj., Hume, E., Rice, K. (eds.). 2011. The Blackwell Companion to Phonology, 1576-1596. Oxford: Wiley-Blackwell.

Miatto, V., Hamann, S., Boersma, P. 2019. Self-reported L2 input predicts phonetic variation in the adaptation of English final consonants into Italian. Proceedings of Proc. 19th International Congress of Phonetic Sciences (ICPhS 2019). Melbourne, Australia.

Miatto, V. 2020. The syllabicity of paragogic vowels in Italian. (Submitted).

Passino, D. 2008. Aspects of consonantal lengthening in Italian. Padua: UniPress.

Repetti, L. 2012. Consonant-final loanwords and epenthetic vowels in Italian. Catalan Journal of Linguistics 11, 167-188. 